\title{
Strategic Study of Fashion Accessories Design: A model for China Undergraduate Education in Fashion

\author{
Junqian Chen
}

Beijing Normal University Zhuhai, School of Design, Zhuhai, China

994195244@qq.com

Keywords: Fashion accessories design, Undergraduate education, Education strategy

\begin{abstract}
By clearly defining the importance of fashion accessories design in fashion design education, this paper argues the shortages of current Chinese fashion accessories design undergraduate education, trying to establish the future fashion accessories education mode through three dimensions of practice, value and method, reflecting the comprehensiveness of the professional knowledge system, the frontier of the curriculum content, and the ambiguity of the discipline boundaries. The education strategy is aiming to cultivate Chinese young designers who could not only have the ability of embodying the Chinese cultural identity and traditional aesthetics in the modern design language, but also hold the view of globalization for brand development.
\end{abstract}

\section{中国时尚配饰设计本科教育策略研究}

\author{
陈君倩 \\ 北京师范大学珠海分校设计学院, 珠海, 中国 \\ 994195244@qq.com
}

关键词：时尚配饰设计; 本科教育; 教育策略

中文摘要.本文通过明确时尚配饰设计在服饰设计教育中的重要性, 论述了当前中国时尚配饰 设计本科教育的不足，试图通过实践，价值和方法三个维度建立未来的时尚配饰教育模式， 体现该专业知识体系的综合性、课程设置内容的前沿性、以及学科界限的模糊性。教育策略 旨在培养中国未来的年轻设计师群体, 使他们不仅具备运用现代设计语言来体现中国文化身 份和传统美学的能力，同时还能秉持全球化的品牌发展观。

\section{1. 引言}

当我们试图讨论中国服饰设计的未来，首先必须回到自己的文化土壤中去重新认识自己 的思维内核。而一个国家的教育理念也不可能朝夕形成，它是一个民族文化思想的缩影。

20 世纪初期至新中国建立，是中国现当代时装的萌兴时段，西方文化的强势入境迫使中 国服装现代化, 民众趋而从之、争相仿效, 形成了风格庞杂的繁兴局面。1949年新中国建立, 中国的社会生活面貌发生了根本的改变, 受东欧与苏联影响, 50年代至70年代的中国服饰产 业发展停滞。直到改革开放之后, 四十年来, 中国人的时尚意识发生了翻天覆地的变化, 中 国服饰与国际服饰逐步接轨。

市场经济的发展使中国人逐渐对消费品有了概念，中国人的消费观念从改革开放前的 “轻消费”, 到改革开放后国家放开了对消费的限制, 再到进入全球化时代的鼓励消费, 使用 户体验变得更为多元化与人性化。实体消费环境成为了生活美学的展览馆, 品牌店更是一个 
品牌精神的体验所。文学、艺术、甚至美食都得以与服装配饰在同一个空间并存，国际时尚 品牌也在越来越多地发展成为综合多品类的生活方式品牌。

中国在改革开放的四十年中，全面经受经济全球化洗礼，在生产与消费两方面越发体现 出难以协调的矛盾。今时今日, 设计创新已被提到国家战略层面。经济全球化使品牌成为其 发源地文化输出的代表, 具有创新能力的品牌充满机遇, 而坚持地域性、文化性特色也保证 了品牌在国际市场上能走的更远。

国际营销大师飞利浦・科特勒早在 21 世纪初期就曾预言: “未来20年，将是中国品牌的高 速成长期。”而国际竞争归根到底是人才的竞争, 我们必须认识到, 文化、创意、产业是一个 有机体。当今中国企业发展急需理解产业发展的国际规则与标准、具备面对全球竞争的工作 能力以及能把握世界潮流发展趋势、具有文化创意设计能力的复合型人才, 而作为专业设计 院校评价的标准，就是要去寻找一种能够产生新设计方式的新教育模式。

\section{2. 中国服饰设计教育的发展}

中国的现代艺术设计教育是在20世纪80年代初正式起步的。1980年，中央工艺美术学院 设立服装设计专业, 开始引进现代设计教育体系, 20 多年来, 中国高等艺术设计教育的数量 和规模有了飞跃进步与发展。特别是在 20 世纪 90 年代末期以来, 在国家“高等教育大众化”政 策的引导下, 制造业迅速发展, 设计人才需求激增, 在就业市场驱动下, 高等艺术设计教育 迅速扩张，目前，中国已经成为全球规模最大的高等艺术设计教育大国。

\section{1 中国的服装设计教育理念构成}

中国的服装设计教育理念主要受三方面影响: 工艺美术思想、现代美术教育、国外设计 教育。课程结构是综合性的、立体性的, 从文化基础课、专业基础课、专业设计课到选修与 辅助课, 总共二三十科课程, 涉及哲学、语言、工学、生物学、理学、美学、自然、社会、 经济等诸多学科。这种课程设置注重系统性, 虽然并没有直接的思维引导与开启课程, 但其 提供了大量思维原料, 利于学生作全面快速的思维联想。这种综合性的知识结构能用最节省 的时间使受教者对各种理论有所了解与掌握, 属于知识输送型。这种教学在中国设计师设计 方式的形成过程发挥了直接作用, 但对设计人才的时尚敏感度及品牌意识的培养明显不足。

\section{2 中西方服装设计教育的差异}

由于我国的艺术设计教育起步较晚, 大量的教育经验都是依靠吸收或模仿国外的先进设 计教育成果所得。以最早实现工业化的西方第一资本主义国家英国为例进行比较, 20 世纪 80 年代开始, 英国设计教育也异军突起, 培养出众多世界知名的成功设计师。英国的理性精神 则表现为“求知”, 因为了解自然和征服自然的需要, 也就有了“逻辑”、“科学”、“摹仿”等有关 “物”的研究发现, 这种习惯自然带入到了英国现当代服装设计当中。相比之下, 中国服装设 计不注重展现时装的生成过程, 设计师更善于用直觉思维思考设计, 注重体悟设计, 在深度 研究时装本身方面较弱。

在设计教学中也可以发现, 英国学生的设计作品差异性大, 虽然设计过程进展缓慢, 但 通过不断地实验, 最终作品的概念与结构成型都较为独特细致。而中国学生虽然反应较快、 绘画水平普遍较好, 能快速出很多方案, 但作品的相似性较大, 这与中国时装设计教育中强 调必须要反复思考的设计方式以及过于注重绘图表现效果有很大的关系。

英国设计教育普遍较为强调对人的启发与引导, 而不是知识与概念的传递, 启发学生形 成自己的观点。研究包括收集、整理和分析资料, 最后的设计方向取决于此, 是整个设计项 目的基础。这种任务驱动式、项目式课程或主题式教学, 促使学生更快适应独立设计, 并能 更好地应对商业品牌设计环境的创新需要。 


\section{3 时尚配饰设计教育的发展}

时尚配饰设计是艺术设计中十分独特的门类。根据功能、材料与制作工艺来分析，帽饰、 手套、围巾都是与服装有着更密切关联的附属配饰产品; 而珠宝、鞋类、包袋、手表、眼镜 等品类却更为独立, 自成一体。

在当今物质生活极大丰富的消费社会中, 人们更多地关注商品的符号价值、文化精神特 性与形象价值, 各类配饰产品也成为了服装之外最容易自由搭配与体现个人风格的形体装饰, 其中，如手袋、首饰、手表、眼镜、丝巾等相对不受年龄身形限制并能更长效使用的产品类 型更是具有广泛的市场。同时，此类产品用材的丰富性与品质控制的灵活性也给产品溢价更 大的利润空间，逐渐成为时尚及奢侈品牌营销中的主角。

十几年间, 时尚经济发展趋势促使西方各大高等院校将时尚配饰专业的本科教育与研究 生教育从服装设计专业中独立出来, 并在教学中强调概念探索与实验创新, 加强与时尚品牌 的合作关系。

目前, 中国的时尚配饰设计教育仍较多依附于服装设计体系，有些发展时间较长的门类 比如珠宝首饰设计又较为独立, 不能与其他配饰类型整合教学。同时, 中国院校面对国际时 尚市场的变化反应相对迟钝，难以应对巨大的人才市场需要。

所以配饰设计教育需要一个具有系统性、科学性与完整性的专业课程体系。也必须认识 到课程不仅是传递知识的一种工具, 更是重新创造我们自身以及社会文化的有效途径之一。

\section{3. 中国时尚配饰设计教育定位}

我国的现代艺术设计教育发展迅速, 但当我们在接受国外新知识与新观念的同时, 也弱 化了几千年来积淀而成的传统审美观与价值观, 而这些具有民族精神的社会意识与文化观念 正是建立具有中国特色的设计艺术体系的必备要素之一。

要构建具有中国特色的设计艺术语言体系, 走适合我国国情的和谐发展道路, 就需要从 传统文化、本土文化、族群文化中吸取养分; 恢复产品与文化的断裂关系, 并使之与现代技 术相结合，重新反省、探讨新的设计文化观。

\section{1 跨学科创新探索}

创新实际上就是一种 “越界”。面对第四次科技革命的汹涌浪潮, 工程、设计还有商业 之间的边界被打破, 设计从一个相对线性的流程性的工作发展成为高度网络化和智能化的行 为, 也成为了连接艺术世界和技术世界的边缘领域。学生必须跨出单一的学科概念, 在多学 科综合中组合出自己新的能力来。

\subsection{T形人才模式}

美国著名设计公司IDEO早在 20 世纪 90 年代中就提出了 “ $\mathrm{T}$ 型人才” 模型的概念，其在设 计创新领域的不断成功与 “ $\mathrm{T}$ 型人才” 的应用也是分不开的。所谓的 “ $\mathrm{T}$ 型人才” 就是：跨专 业领域的换位思考能力（ $\mathrm{T}$ 字上的横轴），同时具备一项深度的专业技能（ $\mathrm{T}$ 字上的纵轴）。

所以, 时尚配饰设计本科教学体系 (四年制模式) 也可以通过纵向和横向能力需要涵盖 的知识范围、设计类别、材料与技术的掌握以及社会价值的交叉性来梳理和建立（见图1）。

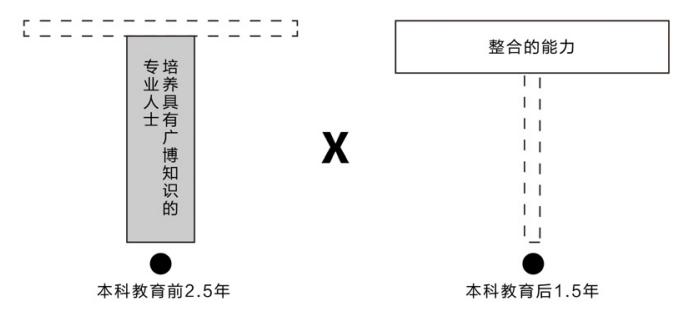

图1 时尚配饰设计本科教育的 “ $\mathrm{T}$ 形人才” 模型 
不仅培养学生的审美能力与表达技能, 更应该培养学生从宏观、系统、整体的角度去把 握与认识专业体系, 并运用创造性思维去发现、分析和解决问题的能力的训练。通过反复的 实践将自己的设计理念现实化, 形成独特的个人艺术风格。同时, 也不能一味强调个性化的 观念创新, 而忽略社会、市场、大众以及环境的需求, 从时尚、生活方式、技术、环境、道 德、社会文化等多个方面去培养创造力, 同时允许学生向不同的方向发展, 从事各种角色。

\section{3 时尚配饰设计教育发展理念}

具体的课程目标是一个课程体系的灵魂和一切教学活动的出发点, 也是判断学生质量与 评价教学发展水平的依据。我们需要将塑造学生完整而独特的个性放在放在第一位, 促使其 形成一种新型的思维模式, 能通过认识与观察事物的表面现象来自主发现其事物本质属性的 能力。

\subsection{1 以综合为导向的教育发展走向:}

时尚配饰设计是一门与社会发展密切联系的交叉性综合型应用学科，是解决人对于物的 需求问题。其学科的特质体现了该专业知识体系的综合性、课程设置内容的前沿性、以及学 科界限的模糊性。可以将中国传统的设计思维方式与现代先进的设计理论进行科学、系统的 整合, 组成一种跨学科、宽领域的知识结构。并引导学生树立正确的人生价值观与社会责任 感, 明确专业服务意识, 形成与社会发展趋势相适应的经济与市场理念, 为学生构建一个可 持续良性发展的新型专业理念体系。

3.2 .2 以问题为导向的教育发展走向:

随着当代社会的不断发展和新一代信息技术革命的侵袭, 时尚配饰设计专业的课程内容 应当具有时代前沿性, 并向国际化趋势发展。因此, 在专业课程设置的内容中应该融入国际 上先进的艺术设计思想和科技理念, 以及符合世界艺术设计发展趋势的技术手段, 以专业的 研究方法为核心, 通过一系列的方法论课程引导学生通过独立思考来发现问题, 并能从全面 的、开放的、具有时代特色的专业视角出发去研究与解决问题。

3.2.3 以艺术为导向的教育发展走向:

国际著名设计大师乔治・罗亚曾经说过: “设计的内涵就是文化。”可见，设计建立在民 族传统底蕴的基础上, 是一种具有文化倾向的理性选择。要培养学生拥有具备时代特色的、 独特敏锐的专业设计眼光, 就必须有深厚的民族文化素养与传统人文精神来支撑其整个专业 知识的框架。因此, 在专业课程具体内容的设置上, 我们应当在保证专业知识体系具备世界 性、先进性与前沿性的前提下, 补充传统文化教育的课程, 引导学生根植于社会文化的土壤, 以民族传统设计思维为基础, 增强人文修养, 把握历史文脉, 将人文内涵贯彻到专业知识传 授的过程中。

\section{4 校企协同发展}

尽管社会的认同与市场的需求是衡量当代高校艺术设计教育成功与否的重要标杆之一, 然而过度的强调艺术设计专业的社会化与市场化, 并以此作为专业课程设置的价值取向, 必 然会导致专业课程的内容体系在学术性方面的缺失, 减弱了学生对专业知识进行深入的理论 性研究能力; 除此之外, 对市场与商业因素的过分灌输与关注, 容易忽略设计的本质, 不利 于行业竞争的良性循环。

企业与高校应当共创课题, 依托地区性制造产业优势, 利用高校交叉学科人才培养与课 题研究的优势, 互相学习, 共同成长, 以科学的方法研究产业特性、民族文化精髓、社会生 活形态、用户需求、产品开发、商业模式及用户体验, 培养能够引导品牌前进的设计师, 使 企业走上可持续的品牌发展之路。 


\section{4. 结束语}

在全球化进程中，中国正遭受着严重的冲击。作为世界经济体系中的重要领域，时尚配 饰产业值得中国教育领域积极深入地研究。我们需要通过整合与重组专业学科来发展创新的 设计教育模式，以应对现实世界的复杂性和多样化的挑战。设计教育应采取切实有效的实际 行动来引导和推动这种转变。

\section{致谢}

本文为北京师范大学珠海分校教师科研能力促进计划阶段性成果之一。

\section{References}

[1] Zhao Jian-hua, The Chinese fashion industry: An ethnographic approach, Bloomsbury, 2013.

[2] Lorraine Justice, foreword by Xin Xiang-yang, China's design revolution, The MIT Press, 2012.

[3] Nicholas Addison and Lesley Burgess, Debates in art and design education, Routledge, 2013.

[4] Jane Schaffer and Sue Saunders, Fashion design course: Accessories, Thames \& Hudson, 2012.

[5] LOU Yong-qi, MA Jin, Emerging practices in design, China Building Material Press, 2014.

[6] He Xiao-you, From "made in China" to "created in China" -characteristics and solutions of Chinese industrial design education in the age of new economy, Hundred Schools in Art, 2008.

[7] Qiu Jia-jia, Study on the methods and criterion grasps of current fashion product design, Jiangnan University, Wuxi, 2009.

[8] Bi Yi-chi, A comparison of design thinking between Chinese and British modern contemporary fashion-focusing on cultural traditions, Soochow University, Soochow, 2013.

[9] Dai Da-fang, Research on the relationship between fashion design symbol and Chinese visual thinking, Jiangnan University, Wuxi, 2008.

[10]Chen Ke-qian, The comparative study on curriculum arrangement for art design professional of university between China and USA, Zhejiang Normal University, Jinhua, 2009. 